\title{
La persecución a Leónidas Barletta por comunista: el cierre del Teatro del Pueblo
}

\section{María Fukelman}

Universidad de Buenos Aires - CONICET, Argentina

mariafukelman@gmail.com

Fecha de recepción: 11/02/2018. Fecha de aceptación: 20/03/2018.

\begin{abstract}
Resumen
En el año 1943, luego de que un grupo de militares llegara al poder dando un golpe de Estado -y constituyéndose como la única experiencia de intervención militar ante un gobierno conservador, el Teatro del Pueblo, dirigido por Leónidas Barletta, fue desalojado del edificio de la Av. Corrientes 1530, sede que la Municipalidad le había dado en concesión en 1937, por unos supuestos veinticinco años. A pesar de que los nuevos funcionarios de facto dieron diversas explicaciones sobre esta decisión, la verdadera razón se vinculó, como sostuvo Carlos Fos (2010), con la ideología política de Barletta, afín al Partido Comunista. En el presente trabajo, por lo tanto, abordaremos las polémicas circunstancias de la expulsión y problematizaremos el vínculo que el teatro de Barletta entabló con el Estado y con los partidos políticos.
\end{abstract}

\section{The Persecution of Leonidas Barletta for Being a Communist: the Closing of the People's Theater}

\footnotetext{
Abstract

In 1943 , after a group of military came to power giving a coup d'etat-which came to be the only local experience of military intervention against a conservative government-, the Teatro del Pueblo (People's Theater), led by Leonidas Barletta, was evicted from the building it had received in concession from the Municipality in 1937, supposedly, for a period of twenty-five years. The building was located at 1530 Corrientes Avenue. Despite the new facto officials gave various explanations for this decision, the real reason was linked, as Carlos Fos (2010) has argued, with the political ideology of Barletta, related to the Communist Party. Therefore, in the present work, we will approach the controversial circumstances of the expulsion and we will problematize the link that the theater of Barletta established with the State and the political parties.
}

Palabras clave Barletta; Teatro independiente; comunismo; Teatro del Pueblo; Década Infame; Pearson

Keywords Barletta; Independent theater; Communism; Teatro del Pueblo; Infamous Decade; Pearson 


\section{Breve introducción sobre el teatro independiente}

El teatro independiente surgió en Buenos Aires a partir de la fundación del Teatro del Pueblo, el 30 de noviembre de 1930, impulsada por el escritor y periodista Leónidas Barletta (1902-1975). Si bien, ya desde mediados de la década del 20 se habían llevado a cabo algunos intentos por conformar un teatro independiente - a partir de la fundación de los grupos Teatro Libre (1927), TEA ${ }^{1}$ (Teatro Experimental de Arte, 1928), La Mosca Blanca (1929) y El Tábano (1930)-, el Teatro del Pueblo fue la primera tentativa que alcanzó continuidad en el tiempo. De esta manera, la crítica especializada coincidió en considerarlo como el "primer teatro independiente de Buenos Aires". Esta frase, además, había sido colocada como subtítulo del nombre del teatro, "después de algunos años de labor" (Marial, 1955: 17), en los programas de mano y en las entradas, dando cuenta de la pretensión de originalidad del grupo de Leónidas Barletta, quien, no obstante, había integrado algunos de los intentos anteriores.

En la Argentina, reconocidos estudiosos del teatro (Ordaz, 1946, 1957; Marial, 1955; Pellettieri, 1990, 1997, 2006; Dubatti, 2012; entre otros) caracterizaron al teatro independiente. Para el presente trabajo, optamos por expresar nuestra definición, elaborada recientemente en nuestra tesis de doctorado (2017a). Entendemos el teatro independiente como un modo de producir y de concebir el teatro que pretendió renovar la escena nacional de tres maneras: se diferenció del teatro que ponía los objetivos económicos por delante de los artísticos; se propuso realizar un teatro de alta calidad estética; careció de fines lucrativos. En este sentido, se constituyó como una práctica colectiva contestataria, dado que se opuso al statu quo del teatro de aquellos años e impulsó una organización anticapitalista.

A este núcleo central de definición se le pueden sumar algunos aspectos lindantes e interrelacionados que le aportan cierto matiz romántico al movimiento: 1) la ideología política afín a los partidos de izquierda - y aunque las acciones de los teatros no estaban al servicio de estos, sí funcionaban de forma complementaria-;2) la consideración del teatro como un instrumento de cambio; 3) la intención pedagógica. A su vez, para llevar a cabo estos objetivos, muchos de los teatros independientes desarrollaron una intensa labor en extensión cultural de cara a la comunidad. A este último párrafo no lo hemos incluido en la enunciación principal sobre el teatro independiente porque presenta elementos que no hemos podido corroborar en todos los grupos estudiados. En este sentido, entendemos que el teatro independiente no fue homogéneo ni en sus comienzos ni a lo largo de los años. Por el contrario, creemos que el movimiento de teatros independientes se mostró, desde sus inicios, como un enraizado complejo y rico en su diversidad.

Los motivos de la iniciación del teatro independiente fueron varios, no hubo una única razón, sino que se dio una combinación de factores. Uno de los más importantes fue el objetivo de distanciarse de la escena del teatro profesional de la década del 20, cuyas características no agradaban a Barletta ni a muchos de los intelectuales de la época. Ese contexto teatral estaba mayormente ocupado por obras del denominado género chico (revistas, sainetes, vodeviles), producidas por empresarios con el principal objetivo de ganar dinero. A su vez, los artistas y escritores que conformaron el teatro independiente se encontraban al tanto de las novedades de la vanguardia artística que estaba sucediendo en Europa. Ese también fue un motor para transformar el teatro de Buenos Aires.

Leónidas Barletta ofreció su mirada, en 1931, sobre cómo y por qué se gestó el Teatro del Pueblo, puntapié inicial para la conformación del teatro independiente en la ciudad capital. El director presentó su teatro como una forma artística nueva que llegaba para dar nivel a un ambiente teatral que, a su criterio, se hallaba en ruinas.
1. Hubo una confusión respecto a este nombre. José Marial (1955) lo denominó ambiguamente TEA. Luis Ordaz (1957; no se había referido a este grupo en su primera edición, de 1946) lo llamó Teatro Experimental Argentino. Raúl Larra (1978); Patricia Verónica Fischer y Grisby Ogás Puga (2006); y Jorge Dubatti (2012) también. Años más tarde, Ordaz (1981) lo nombró correctamente como Teatro Experimental de Arte, y lo mismo hicieron Beatriz Seibel (2002), Andrés Monteagudo (2012) y Magalí Devés (2017). 
De este modo, en el número 1 de Metrópolis. De los que escriben para deciralgo, el órgano oficial de difusión del Teatro del Pueblo, afirmó: “(...) no tenemos teatro argentino. Lo poco de bueno que hay aquí, es material de museo, cosa del pasado que sólo puede interesarnos en ese sentido y que huele a sebo de velorio" (Barletta, 1931: s/p). Al mismo tiempo, advirtió: "Para ese teatro de arte que se ambiciona, hemos contribuido fundando Teatro del Pueblo. Puede ser el peldaño inicial para alcanzar lo que se desea" (Barletta, 1931: s/p).

\section{Los inicios del Teatro del Pueblo}

El Teatro del Pueblo se empezó a gestar en el estudio del pintor Guillermo Facio Hebequer (quien luego dibujaría el logotipo que lo caracterizó), pero su creación de palabra se concretó en los salones de la Wagneriana, el 30 de noviembre de 1930. Cuatro meses más tarde, el 31 de marzo de 1931, Leónidas Barletta, Pascual Naccaratti, Hugo D'Evieri, Joaquín Pérez Fernández, José Veneziani y Amelia Díaz de Korn firmaron el acta fundacional oficial del grupo, denominándolo "Teatro del Pueblo. Agrupación al servicio del arte". Este conjunto - al que pronto se sumaron José Pétriz, Juan Eresky, Tomás Migliacci, Mecha Martínez, Josefa Goldar, Anita Grin y Álvaro Sol, entre otros intérpretes y colaboradores- se constituyó como entidad civil por tiempo indeterminado y se dio un Estatuto y dos Reglamentos, uno para la actividad dentro del teatro y otro para afuera. Estos documentos no se pueden observar completos, pero algunos fragmentos están reproducidos en distintas publicaciones. En relación a su organización interna, el Teatro del Pueblo se regía por una asamblea anual, que nombraba los cargos de Director General, Secretario, Delegados y Comisiones.

José Marial ubica el 14 de febrero de 1931 como la primera presentación del Teatro del Pueblo ante el público, en un cine de Villa Devoto. Dicha función contó con el siguiente programa: La conferencia de Mark Twain, El cafetín (canciones), Comedieta burguesa de Álvaro Yunque, y La madre ciega y El pobre hogar de Juan Carlos Mauri, que luego fue repetido en dos salas más de cines de barrio. En la revista Metrópolis, el anuncio del debut (que contempló únicamente a las obras de Yunque y Mauri llevadas a escena en Villa Devoto y Villa Luro) se realizó en el número 4, de agosto de $1931 .^{2}$

Si bien desde los primeros números de esta publicación se menciona la sede de Av. Corrientes 465 como espacio del Teatro del Pueblo, Marial sostiene que esta fue obtenida recién en 1932, después de que el elenco hubiera actuado durante algunos meses en la Wagneriana. No obstante, esta primera casa para el Teatro del Pueblo (Av. Corrientes 465) -en la que solo entraban 120 personas y había sido una lechería-fue cedida por la Municipalidad el 17 de abril de 1931 y la resolución se publicó en el Boletín Municipal cuatro días después. En 1935, el grupo se muda a otra sala - con, al menos, el triple de capacidad - que también le brinda la Municipalidad, sita en Carlos Pellegrini 340. Luego de estar dos años allí, el conjunto sufre su primer desalojo y es trasladado durante un breve tiempo a un subsuelo en Av. Corrientes 1741. Ese mismo año, 1937, el Teatro del Pueblo se muda a la cuarta sala que le concede el gobierno municipal, ubicada en Av. Corrientes 1530.

Ahí, el Teatro del Pueblo pudo desplegarse como un centro cultural integral: abarcaba teatro, danza, pintura, fotografía y conferencias (de las que participaron Victoria Ocampo, Ramón Gómez de la Serna y Samuel Eichelbaum, entre otros); ofrecía distintos cursos (literatura, historia, filosofía, impostación, acústica, música, arte escénico y folklore); y publicaba la revista Conducta. Al servicio del pueblo. También en ese espacio se realizó, en diciembre de 1938, el primer desfile de teatros independientes, del que participaron la Agrupación Artística Juan B. Justo, el Teatro Íntimo, el Teatro Popular José González Castillo y el Teatro del Pueblo. A su vez, distintas
2. Raúl Larra (1978) también sostiene que la temporada oficial del Teatro del Pueblo comenzó en febrero, pero la ubica en la Wagneriana (Florida 936), con Comedieta burguesa y Títeres de pies ligeros, de Martínez Estrada. Empero, el estreno de esta última obra recién se refleja en Metrópolis en octubre de 1931. 
personalidades del mundo visitaron este teatro. De modo que muchos de los artistas masivos que antes habían sido criticados, fueron "fotografiados para demostrar cuán importante eran las representaciones del teatro independiente" (Fischer y Ogás Puga en Pellettieri, 2006: 200). De la Av. Corrientes 1530, el elenco se fue por la fuerza, en $1943^{3}$, cuando fue expulsado en circunstancias polémicas. En este trabajo abordaremos estas cuestiones, problematizando el vínculo que el teatro de Barletta entabló con el Estado y con los partidos políticos.

\section{Las relaciones del Teatro del Pueblo con el Estado y los partidos políticos}

El Teatro del Pueblo se consideró independiente desde el cuarto artículo de sus estatutos, dejando en claro que su independencia era en relación al Estado y a los empresarios teatrales: "El Teatro del Pueblo es independiente y no podrá aceptar subvenciones en dinero efectivo ni ninguna clase de vínculo o negocio con el Estado, empresas comerciales o personas que traben su libre desarrollo o acción" (Larra, 1978: 81).

No obstante, estas palabras, que luego representaron el alma máter del concepto de teatro independiente, no fueron llevadas, tan estrictamente, de la teoría a la práctica. Este es un aspecto sumamente complejo de la agrupación, ya que, si bien a través de los años ha trascendido la imagen pura del Teatro del Pueblo en tanto ejemplo de independencia dentro del movimiento de teatros independientes, aceptó - tal como mencionamos- las cuatro salas que el Estado le cedió. Podría argumentarse que la cesión de inmuebles no significó dinero en efectivo: sin embargo, esa interpretación no se ajusta del todo a la realidad, ya que el Teatro del Pueblo, para funcionar como tal, tenía que disponer de un espacio y, de no haberlo recibido a través de la Municipalidad, tendría que haber pagado por él, por lo que queda claro que la asistencia que el Estado le brindó puede ser leída en términos de un indirecto aporte económico.

Existe, por otra parte, otro artículo en los estatutos del Teatro del Pueblo que se refiere a las conexiones con la política. Jorge Dubatti sostiene que el grupo explicitará una y otra vez que los acuerdos relativos a la sesión de las salas "nunca determinaron ningún tipo de obligación política, moral o estética con los gobiernos de turno" (2012: 80). El investigador advierte el artículo $9^{\circ}$ como una supuesta redención al respecto: "Siendo su misión, puramente artística como excitante espiritual. El Teatro del Pueblo es ajeno a toda tendencia política, religiosa o filosófica" (Larra, 1978: 81). Pero aquí hay otro significativo punto de tensión: el Teatro del Pueblo no fue ajeno a toda tendencia política. En principio, podría considerarse de este modo, ya que Barletta sostuvo que el motivo de su renuncia a la revista Claridad. Tribuna del pensamiento izquierdista (de la que había sido secretario de redacción antes de crear el Teatro del Pueblo) fue que esta se había transformando en una publicación al servicio del Partido Socialista (cfr. 1967: 52). ${ }^{4}$ Además, al poco tiempo de conformar su teatro, este fue considerado falto de ideología (cfr. Larra, 1978: 86) por algunos compañeros (hecho que produjo una escisión pequeña, encabezada por Ricardo Passano, quien luego fundó el Teatro Proletario). Una vez más, en la práctica los postulados no se cumplieron tan rigurosamente: en contra de lo establecido en el mencionado artículo $9^{\circ}$, la revista Metrópolis hizo campaña explícita por la fórmula presidencial de Lisandro de la Torre y Nicolás Repetto (por la Alianza Demócrata Socialista). De manera que, en la contratapa del número sexto, de octubre de 1931, se expresó:

Si después de trabajar diez años por la cultura del país, nuestra palabra tiene algún valor, decimos al pueblo: no puede oponerse a la reacción otra fuerza política que la de la alianza demócrata-socialista. Votad por De la Torre-Repetto. Contribución de Metrópolis, a la solución del problema político (Anónimo, 1931: s/p).
3. A continuación, el Teatro del Pueblo se instaló en la sala de la Diagonal Norte 943, donde continuó sus funciones hasta 1975
4. Otra versión indica que Barletta se fue porque los integrantes de Claridad negaron ante otro medio que él fuera su jefe de redacción (cfr. García Cedro, 2013: 314-315). 
Desde Metrópolis, además, se criticó a los artistas no comprometidos socialmente. De hecho, en la tapa del primer número, como carta de presentación de la revista, se afirmaba: "Mientras el país sufre una de sus grandes crisis políticas, sociales y morales, 'los artistas' realizan la 'fiesta de las artes'. Después quieren estos 'artistas' que el pueblo no los desprecie" (Anónimo, 1931: s/p). Más tarde, desde Conducta, se hicieron declaraciones similares.

¿Pero cómo era la sociedad con la que los integrantes del Teatro del Pueblo se comprometían y demandaban a los demás artistas que también lo hicieran? Como es bien sabido, en 1930, año en que Barletta fundó su teatro, hacía poco más de una década que había finalizado la Primera Guerra Mundial; y que la Revolución Rusa y el posterior surgimiento de la Unión Soviética — que, con la ideología marxista de Lenin, fue la primera nación del mundo cuyo gobierno fue penetrado por el proletariadofueron de vital importancia para los intelectuales de izquierda argentinos. Estados Unidos, por su parte, tuvo un rápido desarrollo económico en la postguerra, hasta que se vio perturbado por la Gran Depresión de 1929. El golpe financiero de la bolsa de valores de Wall Street impactó sobre el sistema capitalista internacional y la grave crisis económica que sobrevino afectó tanto a los países centrales como a las economías periféricas, que demandaban productos manufacturados y exportaban materias primas y alimentos. Durante los primeros años de la década del 30, la sociedad argentina sufrió las consecuencias del reordenamiento de las relaciones económicas internacionales, dado que entró en crisis el tradicional modelo agrario exportador. Asimismo, entre 1916 y 1930, habían gobernado el país Hipólito Yrigoyen (1916-1922; 1928-1930) y Marcelo Torcuato de Alvear (1922-1928), dos exponentes de la Unión Cívica Radical, pero de distintas facciones. En dicho período - sobre todo en la primera presidencia de Yrigoyen - se impulsaron importantes cambios tendientes a la ampliación de la participación ciudadana, la democratización de la sociedad, la nacionalización del petróleo y la difusión de la enseñanza universitaria. Empero, también hubo conflictos sociales, derivados de las graves condiciones de pobreza en la que vivían hacinados muchos trabajadores. ${ }^{5} \mathrm{El} 6$ de septiembre de 1930, los generales José Félix Uriburu y Agustín P. Justo encabezaron un golpe militar que dio inicio a la denominada Década Infame. ${ }^{6}$ El golpe de Estado fue apoyado por grupos políticos conservadores, quienes expulsaron del gobierno a Yrigoyen inaugurando un período en el que volvió el fraude electoral y la exclusión política de las mayorías.

Leónidas Barletta recordó, treinta años más tarde, esas épocas de definición política:

En 1930, es el reflejo cada vez más intenso (sic), de la Revolución de Octubre, la que impulsa a un grupo de intelectuales a combatir la dictadura de Uriburu y tratar de desbaratar la intromisión de los militares en la vida cívica del país. La mayoría de los de Florida se agrupan en AIAPE. En Boedo, en el teatro del mismo nombre, en una concentración que apoya la fórmula Lisandro de la Torre-Repetto, hablan José Santos Gollan, de Florida y Leónidas Barletta, de Boedo (1967: 52).

La Década Infame tuvo cuatro gobiernos, del mismo color político. Al de UriburuEnrique Santamarina le siguieron, a través de elecciones nacionales (pero fraudulentas), los mandatos de Agustín Pedro Justo - Julio Argentino Pascual Roca (1932-1938), Roberto Marcelino Ortiz - Ramón Castillo (1938-1942), y Ramón Castillo (1942-1943). A la fórmula de Justo - Roca se oponía la de Lisandro de la Torre - Nicolás Repetto (por la Alianza Demócrata Socialista), que, como vimos, era apoyada por el grupo de Barletta. El programa de la Alianza contemplaba las aspiraciones de las clases media y obrera en una época de crisis mundial y de creciente desocupación.

No solo al gobierno dictatorial de Uriburu se opuso el director del Teatro del Pueblo. El radical conservador Alvear fue uno de sus blancos preferidos. En Metrópolis, donde
5. A partir de 1850 , Argentina comenzó a ocupar un importante rol como productor de bienes de exportación, lo que trajo aparejado el artículo n-25 de la Constitución Nacional de 1853 , que fomentaba la migración europea para ser utilizada como mano de obra en el proyecto agroexportador. Así, grandes flujos migratorios provenientes, principalmente, de Italia y España llegaron a nuestro país y se calcula que, hacia 1914, la población extranjera ascendía al 42,7\%. Sin embargo, lo que comenzó como una esperanza no se desarrolló así en todos los casos, y muchos extranjeros quedaron relegados a lugares marginales dentro de la sociedad.

6. Este nombre se lo dio el periodista nacionalista José Luis Torres. 
también se difundía el teatro soviético, se le dedicaron varias críticas y burlas. Yrigoyen, los intelectuales que lo apoyaban, y los ex compañeros de Claridad, vinculados al Partido Socialista, también fueron atacados. ${ }^{7}$

Fue bajo la presidencia de Justo y la intendencia de Buenos Aires de Mariano de Vedia y Mitre, ${ }^{8}$ en 1937, que se le otorgó el edificio de Av. Corrientes 1530 en concesión al Teatro del Pueblo, por veinticinco años, para fines artísticos y culturales, mediante la Ordenanza 8612. Este inmueble -inaugurado por el conjunto el 24 de septiembre de 1937 con La escuela de los maridos ${ }^{9}$ de Molière - era un auténtico teatro (antes había sido llamado Teatro Nuevo y Teatro Corrientes) y tenía capacidad para 1250 espectadores. Leónidas Barletta, intentando dejar de lado las cuestiones políticas, explicó la transferencia de la siguiente manera:

El obtener la concesión por veinticinco años de un teatro que iba a ser demolido, podríamos decir que en cierto modo lo conseguimos por una apuesta que hice yo con el Intendente don Mariano de Vedia y Mitre; porque él sostenía, que el pueblo no se interesaba en el teatro de calidad o en el teatro moderno. Entonces yo le dije: (...) Yo le propongo en este mes de marzo, que es el peor de todos para trabajar al aire libre, porque empieza el rocío; en los peores días, porque tomaríamos lunes y martes, que son los días de la semana menos indicados para el teatro; en los peores días del mes porque tomaríamos 26,27 y 28 y la gente no tiene dinero; si nosotros no tenemos más gente que la que tiene $\mathrm{Ud}$. con Pagliaci, entonces yo no vengo más por su oficina; pero si tenemos más gente, Ud. me ayuda a conseguir un teatro para hacer nuestra experiencia. Me dijo: -Aceptado. (...) A las nueve y media, teníamos tres mil seiscientas personas y don Pío ordenó que se esperara un cuarto de hora más, con lo que hicimos casi cinco mil y pico de espectadores; mucho más que con I Pagliaci (...). Y el intendente reconoció su error y reconoció que la gente tiene hambre de cultura, que tiene muchos deseos de cosas de calidad. Y nos ayudó bastante, a pesar de su filiación conservadora (en Raviolo, 1972: 13-14).

La Sociedad General de Autores (Argentores) se manifestó en contra de esta ordenanza. En el acta de la Asamblea General Extraordinaria realizada el 28 de octubre de 1937 - publicada en el Boletín Oficial $\mathrm{n}^{\circ} 16$ de la Asociación, editado en noviembre del mismo año-, se transcribe la carta que los autores redactaron para el intendente de la ciudad de Buenos Aires. Allí los 56 firmantes (entre los que se encontraban José Antonio Saldías, Samuel Eichelbaum, Vicente Martínez Cuitiño y Enrique García Velloso) le solicitaron revisión y reforma de la reciente promulgación, considerando que el Teatro del Pueblo, compuesto por "aficionados", era "una institución, muy respetable si se quiere, pero facultada muy prematuramente para ejercer el dominio exclusivo de los espectáculos que allí se organicen" (1937: 17). A su vez, los autores advirtieron que faltaban algunos géneros populares (como la zarzuela lírica, el sainete, la comedia y el drama popular), sosteniendo que su inclusión dentro del repertorio del teatro sería posible porque "las funciones según la ordenanza no obligan al ‘Teatro del Pueblo' a ocupar diariamente el escenario" (1937: 18).

No obstante, la concesión fue anulada mucho tiempo antes de que se cumpliera el plazo determinado. El 20 de diciembre de 1943, el documento "Derogación de la Ordenanza 8612, que concedió el usufructo de la propiedad Corrientes 1530, para el Teatro del Pueblo. Creación del Teatro Municipal de la Ciudad de Buenos Aires" puso fin a la estadía del Teatro del Pueblo en el edificio que, en la actualidad, ocupa el Teatro General San Martín. Este escrito fue dado a conocer en el $N^{\circ} 7022$ del Boletín Municipal, la publicación oficial de la Municipalidad de la ciudad de Buenos Aires, y consta de dos partes: la primera es un informe redactado por el síndico Enrique M. Pearson dirigido al Secretario de Cultura, Moralidad y Policía Municipal Dr.
7. Tiempo después, ya con la Presidencia de Juan Domingo Perón (1946-1955), el peronismo se convirtió en otro enemigo del Teatro del Pueblo, y del teatro independiente en general. El movimiento, a su vez, era apoyado, según Kive Staiff por una "clase media que veía en el teatro independiente una forma de silenciosa oposición a Perón" (en Pellettieri, 2006: 150).

8. El intendente porteño declaró luego: “Lo mejor de mi administración fue el Teatro del Pueblo" (Larra, 1978: 101).

9. Fue la primera vez que esta obra - como la mayoría de las otras piezas clásicas que Barletta estrenó- se representó en Buenos Aires. La vieron doscientos mil espectadores en dos temporadas. 
Héctor A. Llambías con fecha del 13 de diciembre de 1943; y la segunda, fechada el 17 de diciembre de 1943, es la resolución tomada por Basilio B. Pertiné (Intendente) y Llambías, y su posterior decreto.

El informe de Enrique Pearson pretende brindar un análisis exhaustivo sobre el trayecto recorrido por el Teatro del Pueblo desde la disposición de la Ordenanza 8612 de 1937. Su propósito es aportar los elementos necesarios para justificar el postrero dictamen del Secretario de Cultura, Moralidad y Policía Municipal que dispondrá la derogación de la ordenanza y la creación del Teatro Municipal de Buenos Aires. Teniendo en cuenta que el gobierno de facto que presidía Pedro Pablo Ramírez (continuando a Arturo Rawson) había derrocado al presidente Ramón Castillo y tomado el poder a través de un golpe de Estado, el 4 de junio de 1943 -por otra parte, única experiencia de una intervención militar contra un gobierno conservador-, es sorpresiva la cantidad de explicaciones que se brindan a la hora de tomar una decisión, pretendiendo hacerse de un marco de legalidad del que podría carecer.

Si bien Pearson manifiesta que no existen irregularidades en lo que se refiere al régimen administrativo, critica cuestiones vinculadas al proceder artístico. Entre otras cosas, señala el anonimato de los actores, la falta de formación de los intérpretes y la "inmoralidad" de algunas de las obras representadas. En este punto, toma como ejemplo a La Mandrágora de Nicolás Maquiavelo, que había sido prohibida por la Municipalidad un año antes. En dicho momento, la Sociedad Argentina de Escritores, encabezada por su vicepresidente Eduardo González Lanuza y su secretario José Gabriel, se había expresado repudiando el hecho: "Lo subido del tono pudo haberla hecho clasificar como 'no apta para menores', y ello nos hubiera parecido atinado. Su prohibición, en cambio, nos resulta lesiva para nuestra cultura" (Archivo Luis Ordaz).

A su vez, el síndico menciona el incumplimiento con el compromiso de realizar obras de teatro gratuitas para escolares y estudiantes, pactado en la ordenanza de 1937. Al respecto, cabe destacar que el Teatro del Pueblo cumplió con creces esta disposición. La actriz Rosa Eresky, que también oficiaba de secretaria de la institución, conservó en una carpeta los comprobantes gráficos de las "Funciones culturales gratuitas para estudiantes". Allí se pueden encontrar fotos, cartas de pedidos y notas de agradecimientos de las escuelas por los espectáculos vistos. En la carpeta, con letra manuscrita, Eresky anotó: "La ordenanza comenzó a cumplirse en la temporada de 1938, ya que el teatro se inauguró en setiembre 24 de 1937; es decir, a fines de la temporada escolar. La obligación de dar dos funciones mensuales durante los meses de actuación, fue cumplida con exceso" (Archivo Instituto Nacional de Estudios de Teatro). En 1938, se dieron 46 funciones gratuitas para estudiantes. En 1939 fueron 19; en 1940, 42; en 1941, 32; en 1942, 54; y en 1943, sexto año de la concesión, se contabilizaron 64 comprobantes de funciones gratuitas para estudiantes.

Aunque la pretensión de objetividad en el documento que deroga la ordenanza sea evidente, no puede dejarse de lado que el gran problema, como afirma Carlos Fos en su artículo "La llegada del Estado al viejo Teatro Nuevo", es la postura extremista de Leónidas Barletta: "Pearson guarda para el final de su trabajo las reales cuestiones que motivan su decisión: razones de tinte ideológico" (2010: s/p). Así, el síndico explica:

El señor Leónidas Agesislao Barletta, se halla prontuariado en la sección Orden Social de la Dirección de Investigaciones bajo el № 60.472. Ha colaborado en diversas oportunidades en el diario comunista La Hora (12 de febrero de $1940,1^{\circ}$ de octubre de 1940, 11 de diciembre de 1940, 3 de octubre de 1941). (...) Aunque los informes policiales no prueban contra el señor Barletta en lo que se refiere a sus actividades extremistas, pues solo se concreta a que recibe propaganda comunista y ha firmado con destacados militantes bolcheviques un manifiesto 
de carácter político, es fácil determinar su ubicación entre núcleos literarios de izquierda aunque, por lo que se sabe, no ha tenido militancia entre esos grupos. En consecuencia, sobre este aspecto solo pueden invocarse pruebas de convicción (Pearson, 1943: 2421-2422).

\section{Y agrega:}

El informante cree de su deber destacar finalmente un aspecto de la actividad del Teatro del Pueblo que merece especial atención.

Hasta hace algún tiempo, la Dirección de dicho organismo organizaba semanalmente lo que dio en llamar "Teatro Polémico", funciones en las que, con intervención del público asistente, se planteaban debates sobre el contenido y mérito de las obras representadas.

Tal procedimiento, aceptable y hasta plausible en un ambiente de cultura verdadera, fue pretexto en el caso del Teatro del Pueblo, para renovadas sesiones de subido color extremista, en las que no se ahorraron manifestaciones y discursos ofensivos para la Religión Católica, la Patria y los más puros sentimientos nacionales. De ello podrían obtenerse varios testimonios, ya que fueron muchos los ciudadanos conscientes que asistieron a dichos debates con la sana intención de que en ellos llegara a escucharse una voz argentina (Pearson, 1943: 2422-2423).

Esta no fue la primera vez que el Teatro del Pueblo había sido acusado de comunista. Algunos años antes, José Assaf, en su libro El teatro argentino como problema nacional (1937), le había dedicado un extenso apartado al teatro de Barletta, espacio al que, tanto él como algunos predecesores, acusaban de "hacer obra comunista" (1937: 84). $\mathrm{El}$ autor clasifica al teatro de masas en tres posibles categorías: religioso, fascista o comunista; y elige la última para encasillar a Barletta y su grupo: "Y como él no es cristiano práctico, y como la mayoría de sus colaboradores militan en la izquierda o simpatizan con ella, la consecuencia no puede ser más que una: este teatro de masas tiende al comunismo" (Assaf, 1937:85). Assaf, ejemplifica su análisis con varias obras de autores nacionales que se habían estrenado en el Teatro del Pueblo, como La cueva caliente de Raúl González Tuñón, Saverio, el cruel de Roberto Arlt y Tedio de Nicolás Olivari. Estas piezas serían opuestas a las representaciones de los clásicos que sí celebra el crítico, por lo que termina preguntándose:

¿Qué queda por pensar, entonces, de esto que para nosotros es contradictorio? 0 bien que se trata de errores involuntarios subsanables en el futuro, o bien que el director del Teatro del Pueblo simpatiza demasiado con el teatro de propaganda izquierdista, intelectual en el sentido que la palabra tiene de elaboración artificiosa y falsa; negación, en fin, del teatro (Assaf, 1937: 95).

Pero volvamos a la derogación de la Ordenanza 8612. Como ya hemos mencionado (Fukelman, 2014), Pearson también ofrece cuestionamientos que fueron enunciados por sus entrevistados, figuras y representantes de entidades del quehacer teatral argentino a quienes creyó oportuno preguntar sobre la actividad del Teatro del Pueblo. Sus testimonios funcionan como aval para sus conclusiones. Los consultados fueron José Antonio Saldías, director del Instituto de Estudios del Teatro de La Comisión Nacional de Cultura; Antonio Botta, presidente interino de Argentores, Nicolás Fregues, presidente de la Asociación Argentina de Actores; y Héctor Quiroga, presidente de la Sociedad Argentina de Empresarios Teatrales. La falta de apoyo de Argentores al Teatro del Pueblo se da por segunda vez, ya que, como advertimos en las páginas anteriores, tiempo atrás se había manifestado en contra de que le otorgaran la concesión. 
El notario municipal culmina advirtiendo que la estadía del Teatro del Pueblo en el edificio de la Av. Corrientes 1530 no ha aportado lo suficiente al arte como para que este grupo siga teniendo el beneficio especial de la concesión. A continuación, y a raíz de las conclusiones brindadas por Pearson, el intendente Pertiné y el secretario Llambías resuelven derogar la Ordenanza 8612, y decretar la creación del Teatro Municipal de Buenos Aires, presentando a su futuro director (Fausto de Tezanos Pinto) y disponiendo las características de este espacio cultural. En relación a esto, se comunica que, dentro de él, habrá sitio para los teatros independientes. Esta novedad y el hecho de que se mencione que el Teatro del Pueblo no tiene ninguna distinción por sobre los demás teatros, como para obtener semejante deferencia por parte de la Municipalidad, están brindando un mensaje al resto de los elencos, con cierta pretensión de dividir las fuerzas internas del movimiento. Los representantes del Estado (como señalamos en Fukelman, 2017b) no quieren plantear una ruptura con el movimiento de teatros independientes, sino que se encargan de puntualizar en el caso del Teatro del Pueblo y su director Leónidas Barletta. Al ver la cantidad de elencos (La Cortina, Teatro Espondeo, Asociación Pro-Teatro Clásico, Teatro Universitario de Buenos Aires, Nuestra Tierra, Teatro Experimental Renacimiento y Agrupación Artística José Antonio Saldías) que participaron de los ciclos que tuvieron lugar en el Teatro Municipal de Buenos Aires en 1944 y 1945, pareciera que la fisura propuesta por Pearson tuvo sus efectos. Sin embargo, el Teatro del Pueblo no fue la única víctima de las decisiones de la Municipalidad. Ese mismo año también se desalojó, de salas que habían sido cedidas, a los elencos del Teatro Juan B. Justo y La Máscara. Para Fos, las protestas y la resistencia de Barletta a la "represión encubierta, pretendían ser licuadas al afectar a varios grupos independientes como La Máscara y la Agrupación Juan B. Justo con medidas restrictivas similares" (2010: s/p). Sobre la decisión de expulsar a los tres conjuntos, Ordaz dijo algunos años después:

El golpe atestado por las autoridades a los tres conjuntos, al retirarles repentinamente los locales de que disponían para realizar sus espectáculos, fue tremendo y, estamos seguros, perfectamente calculado. La actitud correspondía a un plan de vastos alcances políticos que procuraba el estrangulamiento de las actividades artístico-culturales más importantes del país, al mismo tiempo que regimentaba y planificaba desde los textos escolares hasta las libertades ciudadanas. ¿Cómo iba a escapar de ese plan - que destruía lo que no podía controlar-el movimiento de los teatros libres, originado en una inquietud demasiado peligrosa? ${ }^{10}$ (1957: 288).

El día pautado por la Municipalidad para tomar posesión del teatro, Barletta mantuvo las puertas cerradas y no permitió el ingreso. Los funcionarios, entonces, forzaron las entradas y tiraron a la calle los distintos objetos y materiales del Teatro del Pueblo. Larra contabiliza los daños en un millón de pesos de la época. Barletta narra:

De manera que el intendente nos hizo desalojar por una serie de hombres que pertenecían a los diarios fascistas de Buenos Aires. Cuando dejamos el teatro eran cuatro pisos que habíamos llenado de cosas; teníamos 500 pelucas, más de 4000 pares de zapatos y un vestuario de maravilla que nos destrozaron y arrojaron en galpones; no pudimos recuperar nunca todo ese material que habíamos logrado para tener lo que se llama repertorio... (en Raviolo, 1972: 16).

Por este hecho, el fundador del Teatro del Pueblo recibiría, en julio de 1956, una indemnización en concepto de daños y perjuicios por ciento noventa mil pesos. Al poco tiempo de ser expulsado y de comenzar el juicio al Estado, Barletta elaboró y difundió una lista negra con los actores y músicos - entre los que se encontraba su viejo compañero Pascual Naccaratti-que habían actuado en el Teatro Municipal de Buenos Aires con el "nazi" Fausto Tezanos Pinto. Con esta acción, Barletta, lejos de
10. Aquí el autor parece estar integrando bajo el mismo signo al golpe de Estado de 1943 y al gobierno de Juan Domingo Perón, comenzado en 1946 y elegido democráticamente. 
mantenerse separado de la política, estaba "reproduciendo los procedimientos contra los que reiteradamente se había levantado" (Heredia y Díaz, en Pellettieri, 2006: 223).

Si bien la relación con el Estado no termina en esta etapa de la mejor manera, el hecho de que esta haya existido, marca una diferencia con otros grupos de teatro independiente. Por caso tomamos al Teatro Popular José González Castillo, surgido en el seno de la Peña Pacha Camac, que fue obligado a retirarse del espacio que ocupaba en el Café Biarritz cuando este se vendió, en 1938, sin contar con ninguna ayuda del Estado. El periodista Edmundo Guibourg expresó su disconformidad del siguiente modo:

No es extraño, entonces, que obligue a la suspicacia el considerar con qué asombrosa facilidad el llamado Teatro del Pueblo obtuvo de la pasada administración municipal tan desproporcionados favores. (...) Mientras por un lado se despilfarran centenares de miles de pesos, lo bastante para subvencionar a todas las compañías teatrales del país, y ello al solo objeto de asegurar el desenvolvimiento de un núcleo de aficionados, por el otro se conspira contra la existencia de organizaciones de propósitos artísticos que son más especial y más genuinamente populares. Ejemplo flagrante la desaprensión con que se llevó a cabo el desalojo de Pacha Camac, por obra de la municipalidad (en Villa, 2015: 166).

\section{Palabras finales}

A lo largo de este trabajo, hemos abordado los vínculos que entabló el Teatro del Pueblo con el Estado y con los partidos políticos. Hemos considerado tanto las maneras en que el grupo se autopercibió (a través de la redacción de sus estatutos) como las formas en que estos preceptos se llevaron, o no, a la práctica. Asimismo, nos hemos centrado en la relación que se entabló entre el Teatro del Pueblo y la Municipalidad de la ciudad de Buenos Aires para lo que fue la cesión del inmueble más importante en el que se desarrolló el conjunto. En este sentido, advertimos las circunstancias particulares en las que se ejecutaron la Ordenanza 8612 en 1937, y la derogación de la misma en 1943, dando cuenta de que la conexión entre el teatro y el Estado fue activa.

Del mismo modo, la ligazón del teatro con los partidos políticos también se hizo evidente, ya que si bien Barletta, durante los primeros años del Teatro del Pueblo, disparó dardos hacia varios costados, pretendiendo, quizás, mostrarse opositor a todo el sistema político, no dejó de sentar su propia posición ni de hacer campañas explícitas, ya sea a favor de una fórmula presidencial, o en contra de colegas. A su vez, si bien se mantuvo apartidario, en el sentido más estricto de la palabra, hacia el final de su larga carrera decidió afiliarse al Partido Comunista, espacio al que tantas veces le habían atribuido pertenecer. Así lo comunicó en un homenaje que le brindó el Comité Central del Partido Comunista en ocasión de su último cumpleaños: "No somos más que modestos escritores. Sin partido. Nunca lo tuvimos. Quizá sea este uno de nuestros defectos. Por eso, compañeros, para repararlo, les pido que el día de mi muerte, coloquen en mi ataúd el carnet del partido" (en Larra, 1978: 239). 


\section{Bibliografía}

"Anónimo (1931). “Metrópolis”. Metrópolis (1), s/p.

"Anónimo (1931). “Votad por De la Torre-Repetto”. Metrópolis (6), s/p.

"Archivo Instituto Nacional de Estudios de Teatro, Teatro Nacional Cervantes.

» Archivo Luis Ordaz. Instituto de Historia del Arte Argentino y Latinoamericano, Facultad de Filosofía y Letras, Universidad de Buenos Aires.

»Assaf, J. (1937). “Teatro del Pueblo". En El teatro argentino como problema nacional. (83-95). Buenos Aires: Criterio.

" AA.VV. (1937). "Asamblea General Extraordinaria del Jueves 28 de octubre de 1937”. Boletín Oficial de la Sociedad General de Autores (16), 13-18.

» Barletta, L. (1931). “Consideraciones sobre el Teatro del Pueblo”. Metrópolis (1), $\mathrm{s} / \mathrm{p}$.

"Barletta, L. (1967). Boedo y Florida. Una versión distinta. Buenos Aires: Metrópolis.

"Devés, M. (2017). “El Teatro Experimental de Arte: entre las vanguardias soviéticas y El Teatro del Pueblo de Romain Rolland". En Ansaldo, P.; Fukelman, M.; Girotti, B.; y Trombetta, J. (comp.), Teatro independiente. Historia y actualidad. (27-45). Buenos Aires: Ediciones del CCC.

»Dubatti, J. (2012). Cien años de teatro argentino: del Centenario a nuestros días. Buenos Aires: Biblos.

»Fischer, P. y Ogás Puga, G. (2006). “El Teatro del Pueblo: período de culturalización (1930-1949)”. En Pellettieri, O. (ed.), Teatro del Pueblo: una utopía concretada. (159-212). Buenos Aires: Galerna.

»Fos, C. (2010). “La llegada del Estado al viejo Teatro Nuevo”. Memoria (10), s/p.

»Fukelman, M. (2017a). El concepto de "teatro independiente" en Buenos Aires, del Teatro del Pueblo al presente teatral: estudio del período 1930-1944. Tesis de doctorado, Facultad de Filosofía y Letras, Universidad de Buenos Aires. Inédita.

» Fukelman, M. (2017b). “Un recorrido por el Teatro del Pueblo, primer teatro independiente de Buenos Aires". En Ansaldo, P.; Fukelman, M.; Girotti, B.; y Trombetta, J. (comp.), Teatro independiente. Historia y actualidad. (47-66). Buenos Aires: Ediciones del CCC.

»Fukelman, M. (2016) “La política y lo político en vínculo con el teatro independiente”. Conjunto. Revista de teatro latinoamericano (179), 75-84.

» Fukelman, M. (2014). “Recuperación de documentos del teatro independiente: 'el informe Pearson'”. En Margarit, L. (comp.), VI Congreso Argentino Internacional de Teatro Comparado: Cartografías del Teatro del Mundo. Actas. (s/p). Buenos Aires: Ediciones del CCC.

" García Cedro, G. (2013). Ajuste de cuentas. Boedo y Florida entre la vanguardia y el mercado. Buenos Aires: Santiago Arcos editor.

》 Guerrico y Aliverti, A. (1931). "Se concede un local municipal a la sociedad 'Teatro del Pueblo’”. En Boletín Municipal de la Ciudad de Buenos Aires 8 (2521), 739.

» Heredia, M. y Díaz, S. (2006). “La nacionalización del teatro independiente: 
Teatro del Pueblo (1949-1960)". En Pellettieri, O. (ed.), Teatro del Pueblo: una utopía concretada. (213-275). Buenos Aires, Argentina: Galerna.

»Larra, R. (1978). Leónidas Barletta. El hombre de la campana. Buenos Aires: Conducta.

»Llambías, H. y Pertiné, B. (1943). “Creación del Teatro Municipal de la Ciudad de Buenos Aires". Boletín Municipal de la Ciudad de Buenos Aires XX (7022), 2423-2424.

"Marial, J. (1955). El teatro independiente. Buenos Aires: Ediciones Alpe.

" Monteagudo, A. (2012). “El teatro de las tinieblas". En Vitagliano M. (comp.), Boedo. Políticas del realismo. (117-132). Buenos Aires: Título.

" Ordaz, L. (1946). El teatro en el Río de La Plata - Desde sus orígenes hasta nuestros días. Buenos Aires: Futuro.

»Ordaz, L. (1957). El teatro en el Río de La Plata-Desde sus orígenes hasta nuestros días. Buenos Aires: Ediciones Leviatán.

»Ordaz, L. (1981). “El teatro independiente”. Capítulo (88), 25-48.

»Pearson, E. (1943). “Derogación de la Ordenanza 8612, que concedió el usufructo de la propiedad Corrientes 1530, para el Teatro del Pueblo. Creación del Teatro Municipal de la Ciudad de Buenos Aires". Boletín Municipal de la Ciudad de Buenos Aires XX (7022), 2420-2423.

»Pellettieri, O. (1990). Cien años de teatro argentino. Buenos Aires: Galerna.

»Pellettieri, O. (Ed.). (2006). Teatro del Pueblo: una utopía concretada. Buenos Aires: Galerna.

》Pellettieri, O. (1997). Una historia interrumpida. Teatro argentino moderno (19491976). Buenos Aires: Galerna.

" Raviolo, J. (1972). “Leónidas Barletta y el Teatro del Pueblo”. En Teatro’70 (26/29), 7-19.

"Seibel, B. (2002). Historia del teatro argentino. Desde los rituales hasta 1930. Buenos Aires: Corregidor.

»Villa, M. (2015). José González Castillo. Militante de lo popular. Buenos Aires: Corregidor. 